\title{
TRADE-OFFS IN RESOURCE USE: IMPLICATIONS FOR STATE ECONOMIC DEVELOPMENT
}

\author{
Jill L. Findeis and Norman K. Whittlesey*
}

As resources become scarcer, the trade-offs between alternative uses become more of an issue, particularly when resource utilization is influenced by public investment decisions rather than by the private marketplace. The continuing expansion of agriculture through federally subsidized investment in irrigation has raised issues regarding the distribution of water between irrigated agriculture and hydroelectric power generation. Clearly, both alternative uses contribute to economic development: the development of additional irrigation has traditionally been used as a strategy to promote rural development in the United States, while hydroelectric power generation augments the nation's supply of domestically produced energy. While in some cases these alternatives do not conflict, in cases where increased irrigation development implies decreased hydroelectricity generation, the efficacy of developing more land for agricultural use becomes questionable. This is particularly true in light of the supply control problem facing U.S. agriculture today. From the public's perspective, the use of federally-provided public funds to expand irrigated agriculture while simultaneously controlling agricultural supply through government programs is contradictory policy.

The rationalization for increasing irrigation development in light of these concerns is often the importance of agriculture to rural development. The development of additional irrigation will create significant income and employment benefits, particularly in agriculture. Whether water resources are used to generate electricity or used to support irrigated crop production or for some combination of these two alternatives will affect the magnitude and distribution of the impacts generated through economic activity. The existence of competing water use

* Assistant Professor of Agricultural Economics, The Pennsylvania State University, and Professor of Agricultural Economics, Washington State University. Washington Agricultural Research Center Scientific Paper Number SP 7088. alternatives implies that trade-offs exist. Moving from the status quo may bring about significant distributional effects, creating gainers and losers as a result of new development.

This study examines the extent to which irrigation development of approximately 800,000 acres in the Columbia River Basin stimulates secondary economic activity in Washington State. Irrigation of these lands has been proposed, but it is clear that competition between irrigation and hydropower generation is particularly intense in the Basin. While water that has been used for irrigation can be used to generate electricity downstream from the points where return flows re-enter the river, often return flows enter the river after missing one or more dams. Thus, the diversion of more irrigation water in the Basin will impinge on the potential supply of hydroelectricity available to the state by decreasing the capacity of the power supply system, as well as by consuming electricity in the irrigation process.

Findeis and Whittlesey (1984) examined the aggregate implications of irrigation in the Basin, focusing on those sectors most affected by development. This paper focuses on the distributional issues surrounding the expansion of irrigation in the Basin and on a methodology for assessing such issues. The primary and secondary impacts created by new irrigation development will be measured by industry. Estimates of the output, income, and employment created by new development will reflect the positive effects stemming from increased agricultural production, as well as the negative effects created by the use of more expensive thermal energy to replace the hydropower that is lost. These effects will be measured using partitioned simultaneous equations reflecting an updated version of the 1972 Washington input-output transactions matrix, but allowing for simultaneous changes in exogenous prices, output, and final demand.

\section{Methodology}

Input-output (I-O) analysis can be used to 
translate exogenous changes in final demand $(\Delta F)$ into changes in output $(\Delta X)$ for the $n$ sectors of an economy as follows:

(1) $\Delta \mathrm{X}=(\mathrm{I}-\mathrm{A})^{-1} \Delta \mathrm{F}$

where

$\Delta \mathrm{X}=\mathrm{a}(\mathrm{nxl})$ gross output change vector;

$A=a(n \times n)$ matrix of I-O technical coefficients;

$\Delta \mathbf{F}=\mathbf{a}(\mathbf{n x l})$ final demand change vector.

This system, treating $\Delta \mathrm{X}$ as endogenous and $\Delta F$ as exogenous variables, represents the conventional use of $\mathrm{I}-\mathrm{O}$ analysis to relate changes affecting an economy. Departing from this tradition, McKusick et al. (1978) examined the use of input-output for estimating regional development project impacts where the initial effects of the project were to increase capacity for output, and where certain assumptions could be made concerning utilization of the additional output. Using these assumptions, the conventional classification of $\Delta \mathrm{X}$ as endogenous and $\Delta \mathbf{F}$ as exogenous is set aside, but an equivalent structure

(2) $(\mathrm{I}-\mathrm{A}) \Delta \mathrm{X}=\Delta \mathrm{F}$

is retained and imposed to ensure consistency in the accounting of interindustry flows, estimated output, and final demand changes arising from project implementation.

Generalized, the structure in (1) and (2) can be visualized as $n$ equations in $2 n$ variables $\left(\Delta X_{i}\right.$ and $\left.\Delta F_{i} ; i=1,2, \ldots, n\right)$, which must be satisfied. Assumptions regarding initial impacts can be expressed in terms of $n$ consistent independent linear conditions on $\Delta \mathrm{X}_{\mathrm{i}}$ and $\Delta \mathrm{F}_{\mathrm{i}}$. These conditions are applied to (2), permitting a solution for all $2 \mathrm{n}$ variables as measures of the final impacts stemming from the change in economic activity. The simplest conditions are those where $\Delta \mathrm{X}_{\mathrm{i}}=0$ and $\Delta \mathrm{F}_{\mathrm{i}}=0$; these conditions would apply to those industries unaffected by the contemplated economic change. However, those sectors affected by change are initially characterized by $\Delta \mathrm{X}_{\mathrm{i}} \neq 0$ or $\Delta \mathrm{F}_{\mathrm{i}} \neq 0$, allowing for flexibility in evaluating realistic scenarios.

This approach was appended by an I-O methodology provided by Lee, Blakeslee, and Butcher (1977) for analyzing exogenous price changes in conjunction with changes in final demand. The methodology used by Lee et al. (1977) to assess price change impacts is based on the simultaneous solution of three equations that embody the information contained in the transactions matrix, with indexed input and output prices being explicitly modeled. This framework was further adapted in this study to accommodate nonzero intrasector transactions, which changes the original formulation only by the treatment of intrahousehold transactions. The inclusion of intrahousehold transactions was accomplished by including a new term (KY) in the income equation to represent the dollar value of intrahousehold transactions. The three equations developed by Lee et al. (1977) and further adapted for this study can be expressed as follows:

(3) $\mathrm{D}_{\Delta \mathrm{p}}(\mathrm{I}-\mathrm{A}) \mathrm{X}-\mathrm{CY}=\mathrm{D}_{\Delta \mathrm{p}} \mathrm{D}_{\Delta \mathrm{f}} \mathrm{F}_{\mathrm{o}}$

(4) $R=\left[\ell D_{\Delta p}(I-A)-\Delta P_{w} W-\ell D_{\Delta p m} M\right] D_{x}$

(5) $\mathrm{Y}=\mathrm{R} \ell^{\prime}+\Delta \mathrm{P}_{\mathrm{w}} \mathrm{WX}+\mathrm{Y}_{\mathrm{a}}+\mathrm{KY}$

or, analogously, (5) can be rewritten as $\left(5^{\prime}\right)$ :

(5') $Y=\frac{1}{1-K}\left(R \ell^{\prime}+\Delta P_{w} W X+Y_{a^{\prime}}\right)$

where

$D_{\Delta p}=a(n \times n)$ diagonal matrix with indexed prices, $\left(\mathrm{P}_{\mathrm{i}} / \mathrm{P}_{\mathrm{i}}^{\mathrm{g}}\right)$, on the diagonal, where $P_{i}$ represents the new price and $P_{i}^{0}$ the base-period price;

$$
\begin{aligned}
A= & \begin{array}{l}
\text { a }(n \times n) \\
\text { cients; }
\end{array} \\
X= & a(n \times 1) \text { gross output vector; } \\
\mathbf{C}= & \begin{array}{l}
\text { a }(n \times 1) \text { vector of marginal } \\
\text { propensities to consume; }
\end{array} \\
Y= & \text { total aggregate income (a scalar); } \\
D_{\Delta f}= & \begin{array}{l}
\text { a (nxn) diagonal matrix with in- } \\
\text { dexed final demands, } \\
\text { the diagonal; }
\end{array}
\end{aligned}
$$

$F_{0}=a(n \times 1)$ vector of base-period final demands;

$R=a(1 \times n)$ residual income vector; 


$$
\begin{aligned}
& \ell=\mathrm{a}(1 \mathrm{xn}) \text { vector of ones; } \\
& \Delta \mathrm{P}_{\mathrm{w}}=\mathrm{P}_{\mathrm{w}} / \mathrm{Po}_{\mathrm{w}} \text {, a scalar representing }
\end{aligned}
$$
$\mathrm{W}=\mathrm{a}(1 \mathrm{xn})$ labor requirements coeffi- cients vector;
$\mathrm{D}_{\Delta \mathrm{pm}}=\mathrm{a}(\mathrm{n \times n})$ diagonal matrix with in- dexed import prices $\left(\mathrm{P}_{\mathrm{mi}} / \mathrm{P}_{\mathrm{mi}}^{\circ}\right)$, on the diagonal;
$\mathbf{M}=\mathbf{a}(\mathrm{nxn})$ matrix of import coeffi- cients; dustry outputs, where $\mathrm{X}=$ $D_{x} \ell^{\prime}$.
$\mathrm{Y}_{\mathrm{a}}=$ a scalar representing autonomous income;
$\mathrm{K}=\mathrm{a}$ scalar measuring the marginal propensity to consume household services.

Equation (3) specifies that total output by industry $\left(\mathrm{D}_{\Delta \mathrm{p}} \mathrm{X}\right)$, minus interindustry sales $\left(D_{\Delta p} A X\right)$ and interpersonal consumption expenditures (CY), equals exogenous final demand $\left(D_{\Delta p} D_{\Delta f} F_{0}\right)$. Since total income is a function of output, equations (4) and (5) or (5') are required to ensure consistency. Equation (4) determines the residual income earnings accruing to each of the $n$ industries. Since residual income (R) includes proprietor's income, dividends, rent, and interest paid, the residual income accruing to each sector equals the gross income earned in that industry $\left(\ell D_{\Delta p} D_{x}\right)$, minus costs for nonlabor variable inputs $\left(\ell D_{\Delta p} A D_{x}\right)$, wages paid $\left(\Delta P_{w} W D_{x}\right)$, and imported inputs $\left(\ell D_{\triangle p m} M_{x}\right)$. Total aggregate income, $\mathrm{Y}$, is then defined as the sum of three components: residual income ( $\left.R \ell^{\prime}\right)$, total wages paid $\left(\Delta \mathrm{P}_{\mathrm{w}} \mathrm{WX}\right)$, and autonomous income $\left(\mathrm{Y}_{\mathrm{a}}\right)$. This sum is adjusted for the feedback effects of intrahousehold transactions and the income generated through these transactions by the multiplier, $1 /(1-\mathrm{K})$.

To assess output restrictions in conjunction with changes in final demand and exogenously determined prices, equations (3), (4), and (5') are partitioned into two subsets: (a) the k I-0 sectors for which gross output levels are restricted to some predetermined level $\left[\mathrm{X}^{{ }^{*}}\right.$ ]; and (b) the $n-k$ remaining $I-0$ sectors for which changes in final demand $\left[\mathrm{D}_{\Delta \mathrm{k}}^{2 *}\right]$ are known, and may in many cases equal zero. In partitioned form, equations (3), (4), and (5') can be rewritten:

(6)

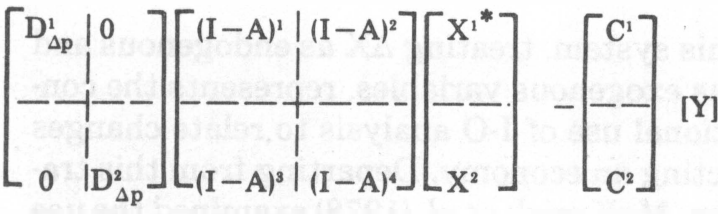

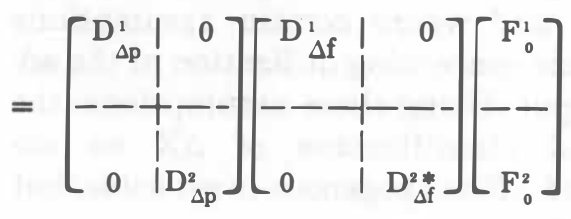

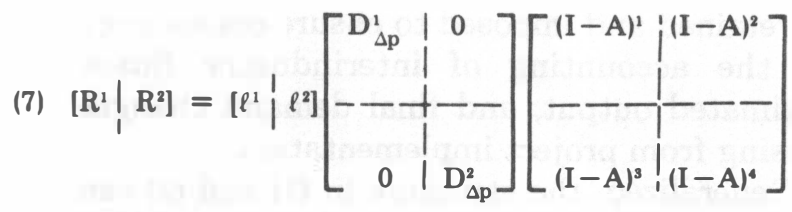

$-\left[\Delta \mathbf{P}_{W^{\prime}}\right]\left[W^{1} \mid W^{2}\right]-\left[\left.\ell^{1}\right|_{\left.\ell^{2}\right]}\left[\begin{array}{cc}D_{\Delta p m}^{1} & 0 \\ \hdashline & \vdots \\ \hdashline 0 & D_{\Delta p m}^{2}\end{array}\right]\left[\begin{array}{l}M^{1} \\ -- \\ M^{2}\end{array}\right] *\right.$

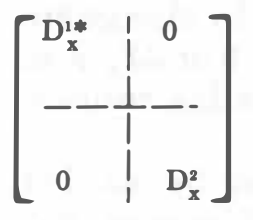


(8) $[\mathrm{Y}]=\frac{1}{1-\mathrm{K}} \quad\left[\mathrm{R}^{2} \mid \mathrm{R}^{1}\right]\left[\begin{array}{c}\ell^{1 \prime} \\ --\cdot] \\ \ell^{2},\end{array}\right]+$
$\left.\begin{array}{l}{\left[\Delta \mathrm{P}_{\mathrm{w}}\right]\left[\mathrm{W}^{1} \mid \mathrm{W}^{2}\right]\left[\begin{array}{c}\mathrm{X}^{1 *} \\ --\end{array}\right]+\left[\mathrm{Y}_{\mathrm{a}}\right]} \\ -\mathrm{X}^{2}\end{array}\right]$

Equations (6), (7), and (8) represent a system of $2 n+1$ equations in $2 n+1$ unknowns: $X^{2}, Y, R^{1}$, $R^{2}$, and $D_{\Delta f}^{1} . X^{1 *}$ and $D_{\Delta f}^{2 *}$ represent the known gross output levels for the first $k$ sectors and the predetermined changes in final demand for the remaining $n-k$ industries, respectively. Equations (6), (7), and (8) can be solved simultaneously by first eliminating $Y$, then $R$. Letting matrix [Q] equal the following:

$$
\begin{aligned}
\text { (9) }[\mathrm{Q}]= & {[(1-\mathrm{K})(\mathrm{I})-\mathrm{C} \ell] \mathrm{D}_{\Delta \mathrm{p}}(\mathrm{I}-\mathrm{A})+} \\
& \mathrm{C} \ell \mathrm{D}_{\Delta \mathrm{pm}} \mathrm{M}
\end{aligned}
$$

the partitioned matrix used to find $\mathrm{X}^{2}$ can be written:

(10)
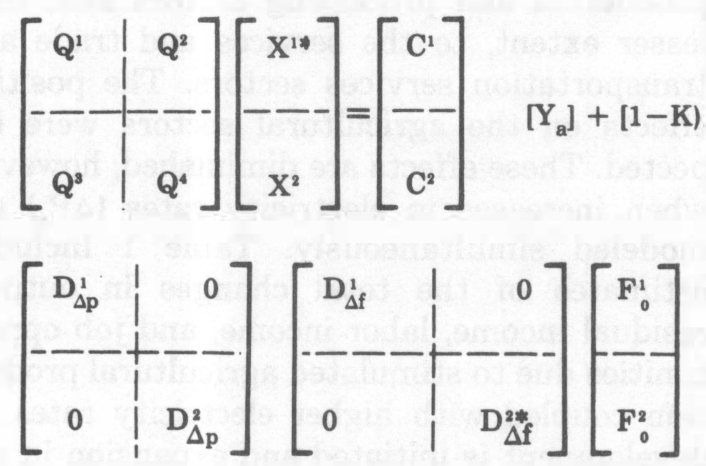

Analyzing each partition separately yields two sets of equations that must be solved simultaneously for $D_{\Delta f}^{1}$ and $X^{2}$ :

$$
\begin{aligned}
& Q^{1} X^{1 *}+Q^{2} X^{2}=C^{1} Y_{a}+ \\
& (1-K) D_{\Delta_{p}} D_{\Delta f}^{1} F_{0}^{1}
\end{aligned}
$$

(12) $Q^{3} X^{1 *}+Q^{4} X^{2}=C^{2} Y_{a}+$ $(1-K) D_{\Delta p}^{2} D_{\Delta f}^{2 *} F_{0}^{2}$
Solving (11) and (12) simultaneously results in equations (13) and (14) which can be solved recursively to determine the unknown gross output levels $\left(\mathrm{X}_{2}\right)$ and final demands $\left(\mathrm{D}_{\Delta \mathrm{f}}^{1} \mathrm{~F}^{1}{ }_{\mathrm{o}}\right)$ resulting from the contemplated change in economic activity.

$$
\begin{aligned}
& D_{\Delta f}^{1} F_{0}^{1}=\left(D_{\Delta p}^{1}\right)^{-1}\left(Q^{1} X^{1 *}+Q^{2} X^{2}-C^{1} Y_{a}\right) / \\
& (1-K)
\end{aligned}
$$

(14) $X^{2}=\left(Q^{4}\right)^{-1}\left(C^{2} Y_{a}+(1-K) D_{\Delta p}^{2} D_{\Delta f}^{2 *} F_{0}^{2}-\right.$

$$
\left.Q^{3} X^{1 *}\right)
$$

The solution values for $\mathrm{X}^{2}$ can be used to determine $\mathrm{D}_{\mathrm{X}}^{2}$, since $\mathrm{X}^{2}=\mathrm{D}_{\mathrm{X}}^{2} \ell^{2}$. Once $\mathrm{D}_{\mathrm{X}}^{2}$ has been determined, solutions for $\mathbf{R}^{1}$ and $\mathbf{R}^{2}$ can be found using equation (7) and $Y$ using equation (8). It is, therefore, possible to solve for changes in sector gross output, residual income, and total income when changes in output, prices, and final demand are used to represent a realistic development scenario.

\section{Empirical Analysis}

The methodology described in this paper was used to measure the simultaneous impacts of changes in output, final demand, and prices. Specifically, increases in agricultural output coupled with higher electricity rates reflecting higher generation costs attributable to irrigation development were analyzed. The base model was the 1972 I-O transactions matrix for the Washington State Economy developed by Bourque and Conway (1977), and updated to 1985 using a RAS iterative technique. To more accurately analyze price changes affecting electricity purchases by different classes of power consumers (i.e., residential, commercial, industrial, and direct-service industrial), the electric utility industry of the updated model was disaggregated into two sectors: (1) electricity generation, and (2) electricity transmission and distribution. Disaggregation facilitated analysis using the methodology described above. If generation costs comprised the same percentage of total electricity costs for each power class, the impact of an exogenous price change affecting the wholesale price of electricity could be measured by increasing the delivered price by the same percentage for each consumer class. However, the ratio of genera- 
tion costs to distribution and transmission costs differs by power class. Since the wholesale cost of electricity was assumed to be identical for all power consumers, with differences in retail rates among consumer classes reflecting differences in distribution and transmission costs, the impacts stemming from an exogenous price change affecting only generation costs could be assessed after sector disaggregation.

Disaggregation of the electric utility sector also facilitated the reestimation of the cost of imported inputs purchased by the electricity generation sector. Since thermal power facilities depend more heavily on imported fuel and equipment than the existing hydropower systems (which historically have produced most of Washington's electricity), the technical coefficient for imports to this sector was increased, with a corresponding decrease in the value-added coefficient. Through changes in the latter coefficient, households are affected by the higher electricity prices that result from a greater dependence on thermal energy.

Following disaggregation of the electric utility sector, the updated 52 industry model was aggregated to a 34 industry Type II model of the Washington economy. The 10 agricultural production and processing sectors and the energy sectors of the Washington model remained disaggregated to facilitate modeling the initial impacts of irrigation development.

The updated, modified Washington model was then used to analyze a production scenario hypothesized to be a realistic representation of the effects of new irrigation development on agriculture. The scenario posited increased field and seed crop, and vegetable and fruit production, as well as expansion of the livestock, meat products, dairy products, and canning and preserving industries. Studies made by other researchers (Estes, 1979; Bbuyemosoke, 1981; Shane, 1978; Hammig, 1978; and O'Rourke, 1980) were used as a basis for allocating the additional production in the field and seed crop and vegetable and fruit sectors to either final or intermediate demand, and as a basis for determining if the additional output being produced would adversely affect the price received for the addtional output. The initial changes that were modeled included increases in output sold to final demand in the agricultural production and processing sectors, price decreases for the field and seed crop and vegetable and fruit production sectors, and an increase in the final demand for transportation services. It was hypothesized that the final demand for transportation services would increase proportionately to the quantity of additional agricultural output demanded due to the necessity of hauling fresh and processed output to market.

This scenario was initially modeled without an increase in electricity rates, and then analyzed with higher energy rates due to the loss of low-cost hydropower affecting the Washington economy. The results reported here provide an insight into the impacts of agricultural development in light of the state's energy situation, as well as an indication of those sectors of the economy which will gain as a result and those industries which will be adversely affected. By examining changes in the residual income vector, the "gainers" and "losers" of new irrigation development can be identified.

\section{Analysis of Results}

New irrigation development in the Basin was shown to stimulate agricultural production in Washington State, with resulting increases in residual income, labor income, and job opportunities accruing primarily to the agricultural production and processing sectors and, to a lesser extent, to the services and trade and transportation services sectors. The positive effects on the agricultural sectors were expected. These effects are diminished, however, when increases in electricity rates $\left(\Delta \mathrm{P}_{\mathrm{e}}\right)$ are modeled simultaneously. Table 1 includes estimates of the total changes in output, residual income, labor income, and job opportunities due to stimulated agricultural production coupled with higher electricity rates. If development is initiated and expansion in the agricultural processing sectors does occur, an additional $\$ 1122.3$ million of output will be generated, creating $\$ 209.1$ million in residual income, $\$ 220.0$ million in labor income, and more than 43,000 job opportunities.

The negative effects on the economy stemming from higher electricity rates are also shown in Table 1. While the negative effects of the rate increase stemming from development are not as large as initially anticipated, it is clear that if the effect of additional irrigation development on electricity rates is ignored, the 
Table 1

Changes in Output, Income, and Employment Resulting from Additional Irrigation Development With Electricity Rate Changes $\left(\Delta \mathrm{P}_{\mathrm{e}}\right)$ Considered $^{\mathrm{a}}$

\begin{tabular}{lccrr}
\hline \hline & $\begin{array}{c}\text { Aggregate } \\
\text { Output } \\
\text { (mil. \$) }\end{array}$ & $\begin{array}{c}\text { Residual } \\
\text { Income } \\
\text { Imil. \$) }\end{array}$ & $\begin{array}{c}\text { Labor } \\
\text { Income } \\
\text { (mil. \$) }\end{array}$ & $\begin{array}{c}\text { Job } \\
\text { Opportunities } \\
\text { (number of jobs) }\end{array}$ \\
\hline Agricultural Production & 278.7 & 92.2 & 22.3 & 14,937 \\
Agricultural Processing & 486.9 & 54.7 & 58.6 & 8,439 \\
Transportation Services & 90.7 & 17.3 & 46.2 & 4,447 \\
Services and Trade & 187.2 & 53.0 & 73.0 & 12,762 \\
All Other Sectors & 78.8 & -8.1 & 19.9 & 2,547 \\
Total & $1,122.3$ & 209.1 & 220.0 & 43,132 \\
Change due to $\Delta \mathbf{P}_{\mathrm{e}}$ & $(-64.5)$ & $(-144.0)$ & $(-17.9)$ & $(-2,510)$ \\
\hline
\end{tabular}

\footnotetext{
In 1972 dollars.

b Excludes entrepreneurial labor.
}

total economic impacts of development will be overstated. This is particularly true in relation to the residual income component representing the returns accruing to the fixed factors of production. When changes in electricity rates are not modeled, residual income gains for the total economy equal $\$ 353.1$ million. When higher electricity rates are analyzed, aggregate residual income decreases by $\$ 144.0$ million, resulting in a net gain of $\$ 209.1$ million. More important, some sectors of the economy experience absolute residual income losses due to new development of irrigation in the Basin. The losses incurred in these sectors are substantial, representing a significant redistribution of income.

By examining changes in residual income earnings on an industry-by-industry basis, the "gainers" and "losers" of irrigation development can be determined. These changes are in- dicated by industry in Table 2. If development is initiated, residual income gains accruing to the agricultural production and processing sectors will total $\$ 147$ million, while earnings in the transportation services, trade, and services sectors will increase by $\$ 70$ million. These sectors are the principal "gainers" from irrigation. Gains in these sectors exceed the total additional residual income earned throughout Washington State.

The remaining sectors of the economy conjunctively experience an absolute residual income loss. These industries are the "losers" from development. Unlike the "gainers" which tend to be concentrated in agriculture, the "losers" are diverse, with the negative impacts of new irrigation development spread throughout the Washington economy. Since electricity rate increases needed to recoup the costs of power replacement represent the major source

Table 2

Residual Income Gains and Losses by Industry

\begin{tabular}{lc}
\hline \hline Industries & Residual Income Gains (Losses) \\
\hline & $(\$)$ \\
Field and seed crops & $56,500,000$ \\
Vegetables and fruits & $18,444,000$ \\
Livestock and products & $16,819,000$ \\
Other agriculture & 485,000 \\
Fisheries & $3,290,000$ \\
Meat products & $10,060,000$ \\
Dairy products & $5,660,000$ \\
Canning and preserving & $31,297,000$ \\
Grain mill products & $1,612,000$ \\
Beverages & 756,000 \\
& \\
Other foods & $5,310,000$ \\
Textiles and apparel & 250,000 \\
Mining & $-603,000$ \\
\hline \hline
\end{tabular}


Residual Income Gains and Losses by Industry

\begin{tabular}{lr}
\hline Industries & Residual Income Gains (Losses) \\
\hline Forestry & 183,000 \\
Wood products & $-1,926,000$ \\
Miscellaneous manufacturing & 699,000 \\
Pulp and paper & $-2,158,000$ \\
Chemicals & $1,624,000$ \\
Petroleum & 97,000 \\
Glass, cement, stone, and clay & $-360,000$ \\
& \\
Iron and steel & $-745,000$ \\
Other nonferrous metals & $-85,000$ \\
Aluminum & $-18,344,000$ \\
Metal products and machinery & $2,297,000$ \\
Aerospace & $-2,090,000$ \\
Transportation services & $17,268,000$ \\
Electric companies & \\
Gas companies & $4,358,000$ \\
Other utilities & $2,003,000$ \\
Services and communications & $2,698,000$ \\
Construction & $29,707,000$ \\
Trade & \\
Total & 698,000 \\
\hline \hline
\end{tabular}

${ }^{a}$ Includes electricity generation, electricity transmission and distribution.

of negative effects, the energy-intensive industries, particularly the aluminum industry, will lose the most if irrigation is undertaken. If new irrigation development occurs, the aluminum industry could lose as much as $\$ 18$ million per year in residual income earnings. In addition, absolute residual income losses will occur in mining; wood products; pulp and paper; glass, cement, stone, and clay; iron and steel; other nonferrous metals; and aerospace, in addition to aluminum. These industries have traditionally been important to the Washington State economy and produced almost 30 percent of all output in the state in 1985.

\section{Conclusions}

The methodology developed in this paper for estimating the simultaneous impacts of changes in final demand, exogenous prices, and output was used to assess the impacts of new irrigation development in Washington State. Due to competition between irrigation and hydroelectric power generation for use of the state's water resources, new development implies that costs must be imposed on some sectors of the economy, particularly on those industries dependent on low-cost hydroelectric power. If irrigation development is initiated, water pre- viously available for the generation of hydroelectricity will be used to support agricultural production, with new higher cost energy sounces being used to replace the energy that is lost. Electricity rates which are already increasing in Washington will be further augmented by the development of new irrigation in the state.

An input-output framework was used to assess the impacts of additional federallyfunded irrigation development in the Columbia Basin. While it is recognized that input-output analysis is limited by the methodology's restrictive assumptions (e.g., fixed technical coefficients and constant prices), input-output analysis remains a useful technique for identifying those industries affected by changing economic conditions and for measuring the direction and relative magnitude of the impacts created.

The methodology proposed in this paper relaxed the I-O assumption of constant prices by allowing for exogenous price changes. The relaxation of this assumption provides a framework for identifying those industries adversely affected by irrigation development, by measuring the extent to which residual income accruing to each industry decreased. In total, it was found that the industries negatively affected by new irrigation development will lose an 
estimated $\$ 26.3$ million if new development occurs. Over time, these industries may pass along losses in the form of higher prices to consumers, adjust their production processes, or be forced to accept lower rates of return on fixed capital. While the effects of these long run adjustments to change cannot be measured in this framework, the methodology used here is useful for identifying those industries that will undergo an adjustment process. Like traditional input-output analysis, this methodology is only appropriate for analyzing short run effects.

Agriculture will be the principal beneficiary of new development, with the positive impacts of new irrigation being concentrated in the agricultural production and processing sectors. The fact that the net impact of new development on the Washington economy will be positive reflects the impact of new development on agricultural output, which is a function of the production scenario assumed. The production scenario analyzed here included increased fruit and vegetable production in addition to increased field and seed crops. It could be argued that even without development, fruit and vegetable production could be expanded elsewhere in the state, thus precluding additional high value crops on the acreages examined in this study. Even if new irrigation development is undertaken, it is plausible that most of the crops grown would be field and seed crops, not vegetables and fruits. The positive net impacts estimated in this study depend on the crops grown on the newly irrigated land.

While input-output analysis can provide information on the total output, income, and employment impacts of an economy, the methodology proposed here provides additional information on the distributional im- pacts of development, at least in the short run. By discerning those industries incurring losses as a result of new irrigation development, decisionmakers can become more aware of the distributional implications of public policy decisions that focus on development.

\section{REFERENCES}

Bbuyemosoke, S. L. The Supply and Demand for Asparagus in the United States. Unpublished Ph.D. thesis, Washington State University, Pullman, 1981.

Bourque, P. J. and R. S. Conway, Jr. The Washington Input-Output Study, Graduate School of Business Administration, University of Washington, Seattle, Washington, 1977.

Estes, E. A. Supply Response and Simulation of Supply and Demand for the U.S. Potato Industry. Unpublished $\mathrm{Ph} . \mathrm{D}$. thesis, Washington State University, Pullman, 1979.

Findeis, J. L. and N. K. Whittlesey. "The Secondary Economic Impacts of Irrigation Development in Washington." Western Journal of Agricultural Economics 9 (1984), 2. 233-243.

Hammig, M.D. Supply Response and Simulation of Supply and Demand for the U.S. Fresh Vegetable Industry. Unpublished Ph.D. thesis, Washington State University, Pullman, 1978.

Lee, G., L. L. Blakeslee, and W. R. Butcher. "Effects of Exogenous Price Changes on a Regional Economy: An Input-Output Analysis." International Regional Science Review, 2 (1977). 15-27.

McKusick, Robert, et al. Regional Development and Plan Evaluation: The Use of Input-Output Analysis. Department of Agriculture, Agricultural Handbook No. 530, 1978.

O'Rourke, A. D. Projections of Market Demand for Pacific Northwest Agriculture to the year 2000. Northwest Agricultural Development Project Report No. 7, Pullman, Washington, 1980.

Shane, R. C. An Interregional Analysis of the Effects of Increased Potato Production, Processing and Transportation Factor Input Costs on the U.S. Potato Industry. Unpublished Ph.D. thesis, Washington State University, Pullman, 1978. 